\title{
Space-time variations of climatic seasons and their correlation with the phenological development of nature in Estonia
}

\author{
Jaak Jaagus*, Rein Ahas \\ Institute of Geography, University of Tartu, Vanemuise 46, 51014 Tartu, Estonia
}

\begin{abstract}
In this paper the spatial and temporal variability of climatic seasons and phenological phases in Estonia are estimated, and the correlation between them is analysed. The start dates and durations of 8 climatic seasons at 23 stations and of 16 spring and summer phenological phases in Estonia between 1946 and 1998 were used for data analysis. The homogeneity of long-term series of climatic seasons was tested using an SNHT (standard normal homogeneity test). The time series can be considered nearly homogeneous. The phenological calendar method was applied. Significant spatial and temporal variability of climatic seasons was detected. The thermal influence of the Baltic Sea is the main factor in the formation of spatial differences. Due to the comparatively cold sea surface, the spring season lasts longer in coastal regions. On average, beginning of summer is observed first in southeast Estonia, at the end of May. In North Estonia summer starts at the beginning of June, and in coastal areas in the middle of June. The onset of the springtime phenological phases has a pattern similar to that of the start dates of spring and summer. The onset migrates over Estonia from southeast to northwest. In coastal areas, climatic seasons during the autumn period start 1 to 5 wk later than in continental Estonia. This spatial difference increases from the beginning of autumn to the beginning of winter. Climatic seasons in the spring period have tended to start earlier over the period between 1891 and 1998. At the same time, seasons in the autumn period tended to start later. In conclusion, the summer season has lengthened significantly (by $11 \mathrm{~d}$ ), while winter has contracted by $30 \mathrm{~d}$. Correlation between start dates of climatic seasons and phenological phases is moderate in Estonia. In most cases, correlation coefficients are statistically significant at the 0.05 confidence level. The highest values are typical for seasons and phases that occur nearly at the same time. In general, the space-time variability of phenological phases is much lower than that of climatic seasons in the same period.
\end{abstract}

KEY WORDS: Climatic season · Phenology · Phenological calendar · Climate change $\cdot$ Estonia Resale or republication not permitted without written consent of the publisher

\section{INTRODUCTION}

The uneven distribution of solar radiation during the year causes the alternation of hot and cold seasons, which is the main characteristic of climate in mid latitudes. The seasonality of weather conditions, in turn, causes seasonal cycles in living nature.

Typical meteorological variables, such as monthly mean air temperature, are not the best variables to describe weather conditions associated with annual cycles in the organic world. Therefore, climatic sea-

*E-mail: jjaagus@ut.ee sons, characterised by their start date and duration, are applied. Instead of using measured values, qualitatively different periods of the year are distinguished, according to strict criteria. A climatic season can be defined as an independent stage in the annual cycle of the climatic component of the natural environment (Galahov 1959). Every season is expected to have its specific complex of weather types, atmospheric circulation, direction of weather changes, etc. In reality, climatic seasons begin at a different time every year, depending on weather conditions. A climatic calendar entails a complex of statistics that describes average annual cycles of climatic seasons. The criteria for 
determining climatic seasons vary in different parts of the world (Flohn 1942, Temnikova 1958, Lamb 1972, Hlavač 1975, Kalnicky 1987, Sladek 1990, Lewik 1996). There is a tradition of analysing climatic seasons in Estonia (Raik 1963, Jõgi 1988, Jaagus 1996).

Phenological phases, which are closely correlated with climatic parameters, have recently emerged as an important focus for ecological research in global modelling, monitoring and climate change studies (White et al. 1997, Schwartz 1999). The detection of the impact of climate change on phenology and the length of the growing season is possible using observation series (Crick \& Sparks 1999, Menzel \& Fabian 1999) or phenological data obtained by satellites (Myneni et al. 1997, Schwartz 1998). For analysing and modelling phenology, scientists use climate parameters such as mean temperature, cumulative sums of daily mean temperatures and precipitation (Schnelle 1955, Heikinheimo \& Lappalainen 1997, Maak \& von Storch 1997, Roltsch et al. 1999), and other aspects, such as length of day or chilling requirement (Flint 1974, Kramer 1994). The calendars-of-nature method (Schnelle 1955, Schultz 1981) in phenology gives more possibilities for the study of seasonality and interrelation between phenological phases of the same or different species (Lieth 1974). Phenological calendars allow the analysis of 3 different parameters describing phenological phases according to start dates, duration and intervals (Jaagus 1996, Ahas 1997) or the combination of calendars with temperature threshold nomograms with determined values (Podolsky 1983).

The main objective of this study is to estimate the spatial and temporal variability of seasonality in Estonian nature. To achieve this, a calendar of nature consisting of data on climatic seasons and phenological phases has to be composed. The calendars-of-nature method should be applied to analyse the variability of seasonality and the interrelation between climatic seasons and phenological phases in Estonia.

\section{MATERIALS AND METHODS}

2.1. Study region. Estonia is located between $57.5^{\circ}$ and $59.5^{\circ} \mathrm{N}$ on the eastern coast of the Baltic Sea (Fig. 1). Despite its small area $\left(45215 \mathrm{~km}^{2}\right)$, it is characterised by remarkable spatial differences in climatic conditions and in the phenological development of nature.

The western part of Estonia lies under the direct influence of the sea while in the central and eastern parts climate gradually becomes more continental.

2.2. Data on climatic seasons. Beginning (or start) dates of climatic seasons were determined for 19 stations in Estonia during the period 1946 to 1998. Definitions of the climatic seasons applied in this study are presented in Section 3. There are some gaps in the data, which were filled using data from the neighbouring station with the most highly correlated start dates. Data from 4 additional stations with shorter observation periods (starting between 1959 and 1964) were also included in the analysis of spatial variability. The duration of climatic seasons was calculated as the difference between the start dates of 2 successive seasons.

Temporal variability, trends, and periodical fluctuations of the long-term series of climatic seasons were analysed using data from Tartu between 1891 and 1998. Tartu is located in southeastern Estonia $\left(58^{\circ} 23^{\prime} \mathrm{N}, 26^{\circ} 43^{\prime} \mathrm{E}\right)$. It is characterised by a moderate continental climate representative of the majority of continental Estonia. The station was relocated within the city twice (in 1893 and 1926). Since 1951, the meteorological station has been located at the airport, $10 \mathrm{~km}$ south of Tartu.

2.3. Homogeneity tests. The homogeneity of the time series of climatic seasons was carefully analysed. There is no analogous data available that can serve as a reference series to test homogeneity of the start dates of climatic seasons in Tartu between 1891 and 1998.

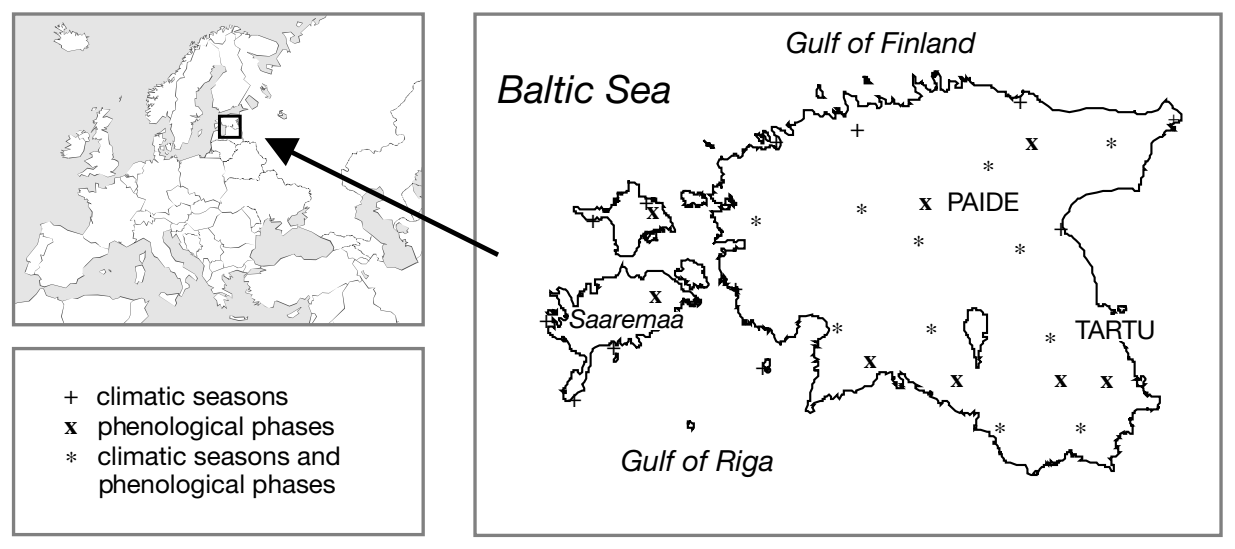

Fig. 1. Location map of Estonia in Europe and of the observation sites in Estonia 
Therefore, only absolute tests such as the well-known von Neumann ratio can be used (Buishand 1982). With the null hypothesis of a constant mean it can be shown that the mean of the ratios is equal to 2. For a nonhomogeneous record the mean tends to be smaller than 2. D. B. Owen (1962) gives a table of percentage points of von Neumann ratio for normally distributed samples.

Another possibility for studying the homogeneity of a series of climatic seasons is to use air temperature data, since the start of climatic seasons depends directly on air temperature. When air temperature series are homogeneous, the time series of climatic seasons should be likewise.

The standard normal homogeneity test (SNHT) was applied in this study to analyse the time homogeneous reference series (Alexandersson 1986, Steffensen 1996, Alexandersson \& Moberg 1997). The test is performed on a ratio or difference series between the candidate station and a reference series. For a homogeneous time series, the test statistic should not exceed a critical $t$ value on a fixed confidence level. The SNHT calculates adjustment statistics for data homogenisation. It was not applied as a correction to inhomogeneous series in this study. It was used only for the estimation of the influence of breaks in the homogeneity of time series of climatic seasons.

The following homogeneity tests were carried out in this study:

- SNHT for start dates of climatic seasons at the 23 stations, the reference series consisting of the mean values of the 6 nearest stations. The results indicated that the data of most stations are homogeneous. For some stations, inhomogeneities during the first or last years of the time series were revealed.

- SNHT for monthly mean air temperature at the 23 stations, the reference series consisting of the mean values of the 6 nearest stations. The temperature series at 11 stations are entirely homogeneous. At the other stations, the main cause of inhomogeneity was relocation of the station. Adjustment statistics automatically calculated by the SNHT were within $\pm 0.5^{\circ} \mathrm{C}$.

- SNHT for monthly mean air temperature in Tartu between 1891 and 1998. The time series from other stations in Estonia, from the closest stations in Finland and Sweden obtained from the NACD data set (Frich et al. 1996), and the long-term homogenised series from Uppsala and Stockholm (Moberg \& Bergström 1997) were used as reference series. Test results determined a significant break in 1950 (all seasons except winter), which corresponds to the relocation of the Tartu station to the airport. Adjustment statistics were -0.2 to $-0.4^{\circ} \mathrm{C}$ (maximum change in spring, minimum in autumn).
- Von Neumann ratios for start dates of climatic seasons in Tartu between 1891 and 1998. The values tend to be near 2.0, indicating homogeneity of the time series. The highest deviations occurred for the start date of early winter and winter. But their absolute values - 1.8 and 2.2 respectively - are above the critical level that indicates that the time series are homogeneous.

In conclusion, the homogeneity test results demonstrate that data of climatic seasons in Estonia are nearly homogeneous. The breaks in air temperature series of 0.2 to $0.5^{\circ} \mathrm{C}$ do not cause significant inhomogeneity in time series of start dates of climatic seasons. The main break in the air temperature series in Tartu after 1950 is accounted for in the time series analysis of climatic seasons.

2.4. Phenological data. Phenological data were obtained from observation programmes conducted by the Estonian Meteorological and Hydrological Institute (1946 to 1995) and by Estonian Society of Naturalists (1951 to 1995). For this study, data of the best quality and coverage was selected:

- The start of pollination of 6 tree species: hazel Corylus avellana L., maple Acer platanoides L., bird cherry Prunus padus L., lilac Syringa vulgaris L., rowan Sorbus aucuparia L., apple Malus domestica L., variety Antonovka, and foliation of birch Betula pendula Roth.

- Nine phases of autumn sown rye Secale cereale L., Estonian variety Sangaste. Its development phases are defined as follows: beginning of vegetationfresh green leafs, daily maximum of air temperature above $+5^{\circ} \mathrm{C}$; stalk formation (cereal) - formation of the lowest stalk node ( 3 to $5 \mathrm{~mm}$ above node); appearance of stalk node-stalk node is $0.5 \mathrm{~cm}$ above the surface, detected manually; ear-half of spike (head of grain) is out of leaf sheath; pollination-opened flower calyxes and anther is visible; milky ripeness - grain has fully developed, inside of grain is soft, plant is still green; waxy ripenessgrain is yellow and plastic; full ripeness-grain is hard; harvesting.

There are 17 observation sites for most of the tree species and 10 for rye (Fig. 1). Because of the lack of data with a similar density and quality, only spring and summer phenophases are analysed in this study. The beginning of a phenological phase is recognised when the phase has been reached by $10 \%$ of the observed plants. About $10 \%$ of the data was interpolated due to clear errors or gaps in observations. Interpolation of time series was carried out by correlation analysis using the mean value of the 2 most highly correlated neighbouring observation points.

To analyse long-term changes, the following time series of phenological data in Paide (central Estonia) 
are used: blossoming of bird cherry, apple, lilac and wood anemone Anemone nemorosa L. during the period 1919 to 1996 (Ahas et al. 1998).

2.5. Statistical analysis. The phenological calendar method (Schnelle 1955, Lieth 1974, Schultz 1981, Podolsky 1983) was applied to analyse space-time variations of the calendar of Estonian nature. Start dates as phenological variables mark certain points in the annual cycle. They have a particular sequence and they are closely correlated with phases of the same season (Gerstengarbe \& Werner 1999). A recurrent annual cycle consists of a sequence of regularly successive phenological phases described in terms of start dates, durations and intervals. Every period distinguished in the annual cycle has its duration, for example, the thermal growing season, the climatic seasons, or the pollination period of rye. Intervals are defined as time periods between any phenological phases.

A phenological calendar contains common descriptive statistics (mean values, standard deviations, extreme values, ranges, distribution parameters, etc.). At first, an average calendar was composed using mean values of climatic seasons and phenological phases during the observational period. The calendar could be graphically represented by an annual circle in which different seasons are distinguished.

Spatial and temporal variation were analysed separately. Spatial standard deviations were calculated using observational data from a number of observation sites, at first, for each year and then averaged over a number of years. Spatial range means a difference between the latest and the earliest mean value among the stations or observation sites. Temporal standard deviation was found on the basis of a single time series and then averaged by stations. Temporal range indicates a difference between the latest and the earliest years in the time series.

Regression analysis was used for estimation of trends and for correlation analysis to estimate statistical correlation between climatic seasons and phenological phases. Significance of correlation coefficients and slopes was estimated by means of the $t$-statistic. The confidence level $p<0.05$ was considered to be suitable for significant correlation of trends. Spatial interpolation using kriging was applied for the drawing of maps.

\section{DETERMINATION OF CLIMATIC SEASONS}

Essentially, climatic seasons are similar to ordinary phenological phases determined and recorded according to start dates. Determination of climatic seasons must follow some important principles. A season should be internally uniform and clearly different from other seasons. The influence of weather conditions on the seasonal development of nature is the leading criterion for dividing a year into climatic seasons. Determination of seasons must also be as simple as possible using uniform criteria. These recommendations permit one to use a large data set and to minimise subjectivity in the determination of start dates of climatic seasons.

Eight climatic seasons have been distinguished in Estonia (Raik 1963, Jaagus 1996). In addition to the 4 main seasons - spring, summer, autumn and winter2 intermediate seasons between autumn and winter (late autumn, early winter) and 2 between winter and spring (late winter, early spring) have been distinguished.

Constant temperature thresholds are the most frequently used possibility for determining climatic seasons. Sladek (1990) for example applied the simplest method by using only 2 temperature thresholds 0 and $+15^{\circ} \mathrm{C}$ for the differentiation of 4 main seasons. For more detailed analysis, it is useful to divide spring and autumn into 2 parts which separate the thermal growing season.

Climatic seasons of the warm half-year are determined according to the pattern of daily mean air temperature. Spring, which begins after the permanent increase of daily mean air temperature above $+5^{\circ} \mathrm{C}$, indicates the start of the thermal growing season (Jones \& Briffa 1995, Carter 1998).

Summer corresponds to a period in which daily mean air temperature is consistently higher than $+13^{\circ} \mathrm{C}$. It coincides with the period favourable for the growth of thermophilic plants. A temperature threshold of $+15^{\circ} \mathrm{C}$ is not a suitable criterion for the summer season in Estonia. During extremely cold summers daily mean air temperature does not permanently rise above this limit.

Autumn begins after a sustained drop of daily mean air temperature below $+13^{\circ} \mathrm{C}$. It is characterised by an increased frequency of cloudy and rainy days, by the first night frosts, and by maturation of apples and summer crops. Late autumn begins with the end of the thermal growing season after the sustained fall of daily mean air temperature below $+5^{\circ} \mathrm{C}$.

Weather conditions in Estonia are very variable, with non-linear seasonal changes in air temperature. Periods of higher and lower temperature usually alternate. Dates when the daily mean air temperature crosses certain thresholds $\left(+5\right.$ or $+13^{\circ} \mathrm{C}$ in this study) are determined following procedures used by meteorological services for many decades.

Once the temperature threshold has been reached, positive and negative differences in the daily temperature minus the threshold value are summed separately. As soon as the absolute value of the sum of negative differences is higher than the sum of the positive differences, the first crossover of the temperature threshold is 
not taken as the start of the respective season and the search for the season's start is continued from this day.

Snow cover is the main factor in determining the climatic seasons during the cold half-year. Early winter (or pre-winter) starts with the first formation of snow cover and with the first cold days when daily maximum temperature remains below zero. It embraces the period with unstable snow cover when freezing and melting alternates. In years when the first snow does not melt after a few days but remains for the entire winter, the early winter season is omitted.

Winter itself begins after the formation of permanent snow cover. The continuous period with cold weather before the formation of snow cover is included in the winter season. Permanent snow cover is defined according to the criteria applied in the former Soviet Union (Drozdov et al. 1989). These include, for instance, the existence of snow cover for a minimum of $1 \mathrm{mo}$. Due to intensive cyclonic activity, winter is quite unstable in Estonia, and is characterised by frequent thaws. During some winters, especially in coastal regions, permanent snow cover does not form at all. In this case, early winter transforms directly into late winter. In which case, it will be more justified to observe winter as one long climatic season (early winter+winter+late winter). But, to avoid gaps in time series and to ease data processing, winter is distinguished every year, although its duration may be less than 1 mo.

Late winter is a period of snow melting at the start of the year. It also includes short periods when snow cover reforms after the disappearance of the perma- nent snow cover. The start date of the snow melting period is the day after which the occurrence of nonmelting days (daily maximum temperature below zero) does not exceed the number of melting days. Early spring begins after the final disappearance of snow cover.

In cases of extraordinary early formation of temporary snow cover in late autumn or its extremely late formation in early spring, these periods were not included into early winter or late winter when they were separated from them by warmer periods with daily mean air temperature above $+5^{\circ} \mathrm{C}$.

\section{SPATIAL VARIABILITY}

Start date and duration of the climatic seasons in Estonia are characterised by a remarkable spatial variability. Statistics of spatial variability are presented in Table 1. Spatial mean start date and duration of climatic seasons were found by averaging mean values at the 19 stations calculated for the period 1946 to 1998. Spatial range here means the difference between the earliest (longest) and the latest (shortest) mean values of the stations. Spatial standard deviations were computed at first for every year, and then they were averaged over time. Statistics for phenological phases from 10 to 17 observation sites were found in the same way.

The highest spatial variability for the start dates of winter ( $5 \mathrm{wk}$ ) is due to the warming effect of the Baltic Sea. In the coastal regions winter begins 3 to $5 \mathrm{wk}$ later

Table 1. Statistics of spatial variability for start dates (a) of climatic seasons determined at 19 stations and (b) of phenological phases determined at 10 to 17 stations in Estonia between 1946 and 1998

\begin{tabular}{|c|c|c|c|c|c|c|}
\hline & \multicolumn{2}{|c|}{ Spatial average } & \multicolumn{2}{|c|}{ Spatial range } & \multicolumn{2}{|c|}{ Standard deviation } \\
\hline & Start date & Duration & Start date & Duration & Start date & Duration \\
\hline \multicolumn{7}{|l|}{ (a) Climatic season } \\
\hline Late winter & $1 \mathrm{Mar}$ & 33 & 7 & 7 & 4.5 & 7.4 \\
\hline Early spring & $3 \mathrm{Apr}$ & 21 & 12 & 18 & 6.2 & 8.7 \\
\hline Spring & 24 Apr & 41 & 11 & 9 & 4.6 & 7.6 \\
\hline Summer & 4 Jun & 94 & 18 & 14 & 7.2 & 8.8 \\
\hline Autumn & 6 Sep & 51 & 14 & 5 & 5.9 & 7.8 \\
\hline Late autumn & 27 Oct & 18 & 17 & 8 & 6.8 & 9.0 \\
\hline Early winter & $14 \mathrm{Nov}$ & 38 & 21 & 19 & 8.6 & 15.8 \\
\hline Winter & $22 \mathrm{Dec}$ & 69 & 35 & 42 & 14.9 & 16.4 \\
\hline \multicolumn{7}{|l|}{ (b) Phenological phase } \\
\hline Pollination of hazel & 12 Apr & & 4 & & 4.6 & \\
\hline Beginning of vegetation of rye & 14 Apr & & 8 & & 4.6 & \\
\hline Rye stalk formation & 2 May & & 9 & & 6.2 & \\
\hline Birch leaf formation & 6 May & & 10 & & 3.8 & \\
\hline Flowering of maple & 11 May & & 11 & & 3.6 & \\
\hline Flowering of bird cherry & 19 May & & 9 & & 3.3 & \\
\hline Flowering of apple tree & 27 May & & 9 & & 3.4 & \\
\hline Flowering of rowan & 31 May & & 7 & & 3.1 & \\
\hline Pollination of rye & $18 \mathrm{Jun}$ & & 5 & & 3.2 & \\
\hline
\end{tabular}



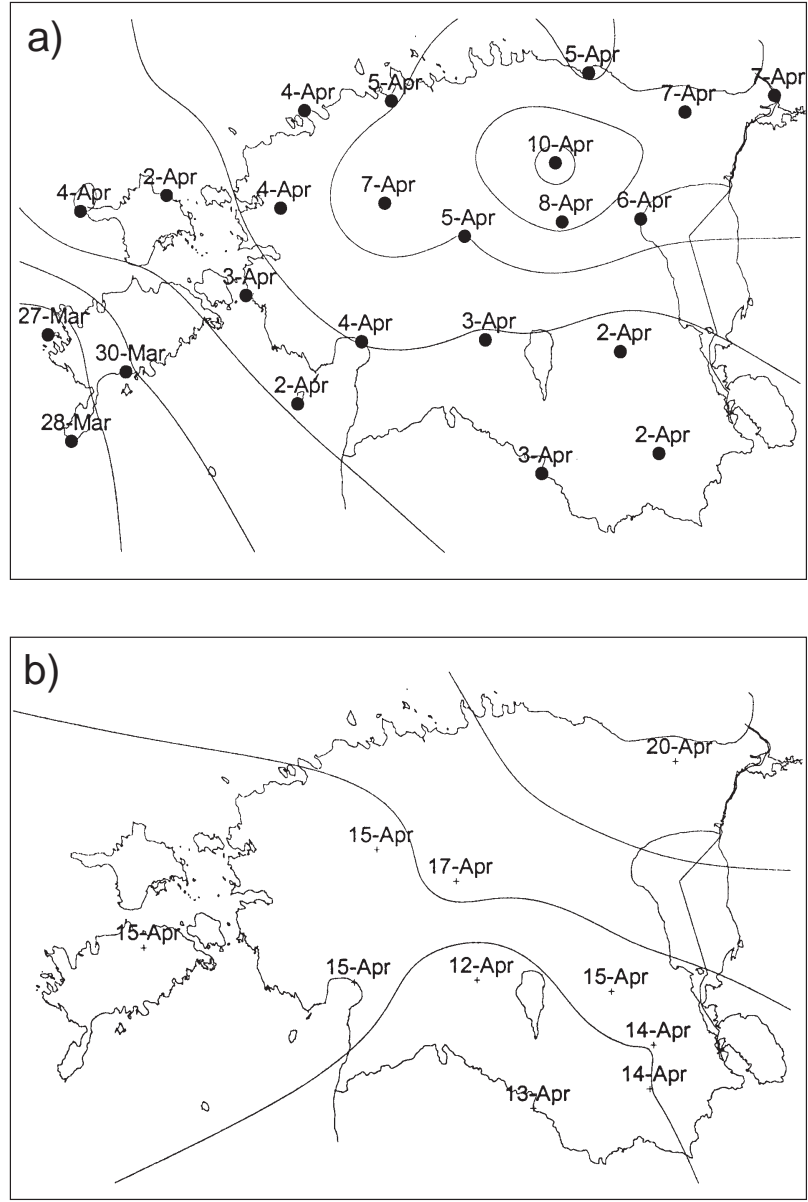

Fig. 2. Mean start date of (a) early spring and (b) vegetation of rye (variety Sangaste) (isoline interval $=2 \mathrm{~d}$ )

than in the inland parts of continental Estonia. Macroscale synoptic processes result in the lowest spatial variability for the start dates of late winter. Due to advection of a warmer air, snow melting begins more or less at the same time over the whole territory of Estonia.

The range of spatial variability of phenological phases in Estonia is rather constant -7 to $10 \mathrm{~d}$ on average. This range is smaller than that of the start dates of climatic seasons. This can be explained by the wider spatial coverage of data on climatic seasons, and the use of more data from coastal stations.

There are 3 different patterns of climatic season start dates during a year. The earliest beginning of late winter and of early spring is observed on the western coast of Saaremaa Island (Fig. 2a). Usually, this region remains under the influence of the ice-free part of the Baltic Sea throughout the winter. Therefore, the snow cover is thin and melts earlier than in continental Estonia. The longest duration of snow cover occurs in the
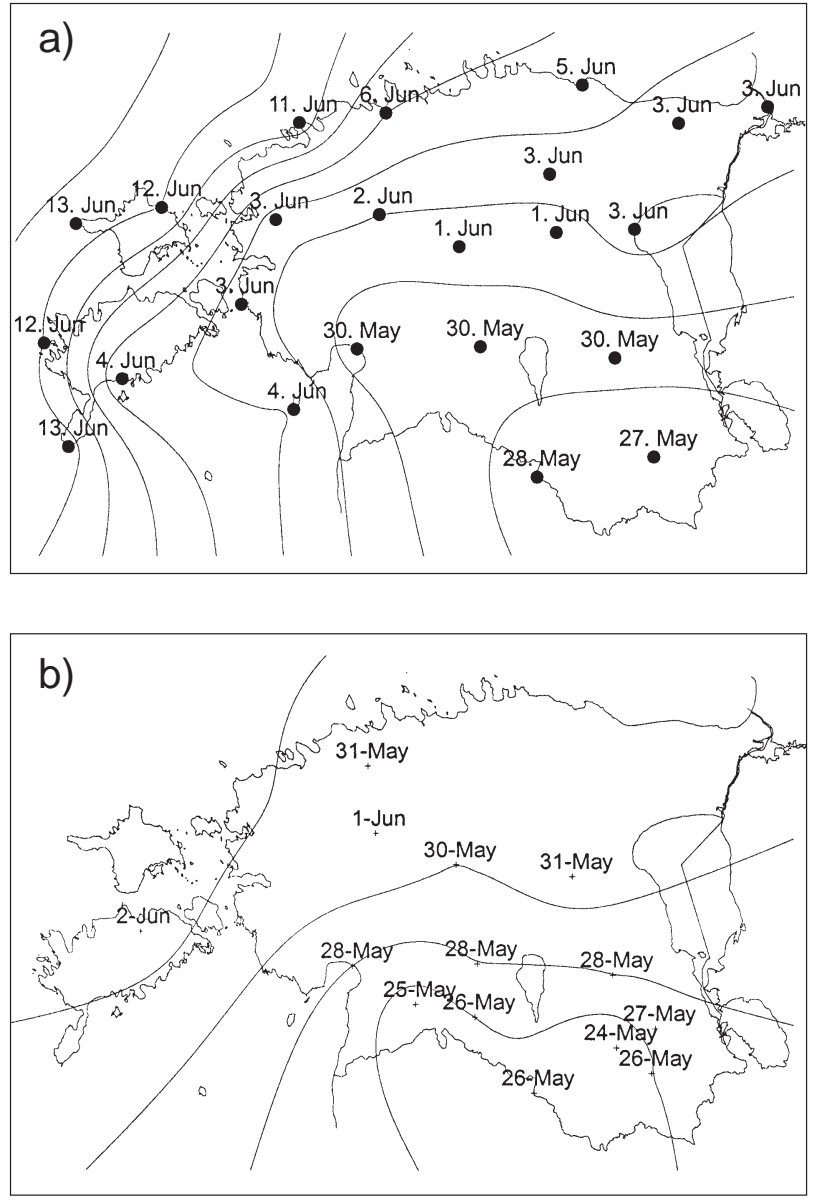

Fig. 3. Mean start date of (a) summer and (b) the beginning of apple tree (variety Antonovka) blossoming (isoline interval = $2 \mathrm{~d}$ )

northeast of Estonia. The start of the 2 climatic seasons migrates from southwest to northeast. The comparatively high spatial variability in the start date of early spring is due to substantial local differences in the final melting of snow cover. The spatial distribution of the start date of early spring is similar to that of the beginning of the vegetation period of autumn sown rye (Fig. 2b) and other phenological phases occurring at the same time (e.g. pollination of hazel).

Another pattern is observed for the spring and summer dates (Fig. 3a). These seasons begin first in the southeast of Estonia. This can be explained by different factors: greater influence of warm air coming from the south and southeast, lesser influence of the arctic inflow from the north and north-east, lack of the influence of the cold Baltic Sea, and more intensive solar radiation. The latest starts of spring and summer are observed on the northern and western coasts of Estonia. Coastal regions are the coldest in spring due to the thermal inertia of the sea surface. The mean difference 


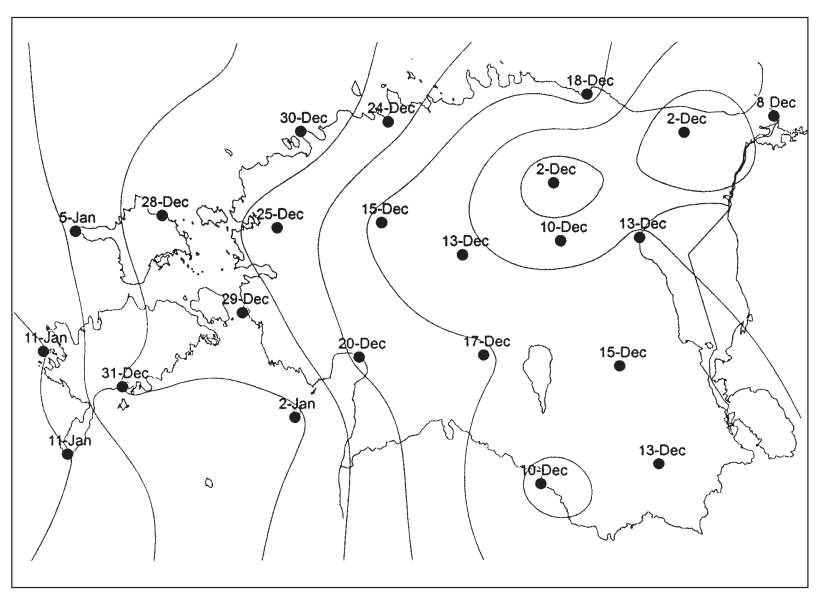

Fig. 4. Mean start date of winter displaying the largest spatial differences - $35 \mathrm{~d}$ - between eastern (continental) and western (marine) Estonia (isoline interval $=5 \mathrm{~d}$ )

in the beginning of summer between south and north Estonia is 1 to $2 \mathrm{wk}$, while the difference between the Southeast and coastal stations of the West-Estonian Archipelago is up to $18 \mathrm{~d}$. The spatial pattern of springtime phenological phases has a pattern similar to the beginning of spring and summer. Typical phenological phases during the same period are the onset of blossoming of rowan, lilac, and apple trees (Fig. 3b).

Spatial differences marking the start of climatic seasons during the second half-year are even more remarkable. They increase from the beginning of autumn up to the beginning of winter. Cooling starts in the northern and northeastern part of the mainland (Fig. 4). This re- gion is the most frequently affected by the inflow of cold arctic air from the north-east. The coastal regions of west Estonia are characterised by much higher temperatures. The spatial difference increases from $14 \mathrm{~d}$ in autumn to $35 \mathrm{~d}$ in winter (Table 1). On the islands of the West-Estonian Archipelago, autumn begins 1-2 wk later, late autumn 1.5-2.5 wk later, early winter 1.5-3 wk later, and winter 2-5 wk later than in east Estonia.

The duration of climatic seasons is also characterised by a high spatial variability (Table 1). Early spring is much longer in the coastal regions due to the cooling effect of the sea. Significant spatial differences are observed in the mean duration of summer. Summer in south Estonia is 10 to $12 \mathrm{~d}$ longer than in north Estonia. The longest summer is observed in the coastal zone of the shallow Gulf of Riga, where sea-surface temperature increases substantially during summer. Early winter and winter have the highest spatial variability (Table 1). In coastal areas, winter is nearly 2 times shorter than in northeast Estonia.

\section{CORRELATION BETWEEN START DATES OF CLIMATIC SEASONS AND PHENOLOGICAL PHASES}

Phenological development in nature is closely related to weather conditions. Early and warm springs coincide with the earlier occurrence of phenological phases. Correlation coefficients between start dates of climatic seasons and phenological phases in Estonia averaged over 9 stations (Fig. 1) between 1947 and 1996 are presented in Table 2.

Table 2. Correlation coefficient (Corr.) between start dates of climatic seasons and phenological phases (in chronological order) averaged over 9 stations with parallel observations between 1947 and 1996; the mean difference (Diff.) between the correlation coefficients calculated for 1972 to 1996 and for 1947 to 1971 is shown. Bold values: correlation is significant at p < 0.05 confidence level for each of the stations

\begin{tabular}{|c|c|c|c|c|c|c|c|c|}
\hline \multirow[t]{2}{*}{ Phase } & \multicolumn{2}{|c|}{ Late winter } & \multicolumn{2}{|c|}{ Early spring } & \multicolumn{2}{|c|}{ Spring } & \multicolumn{2}{|c|}{ Summer } \\
\hline & Corr. & Diff. & Corr. & Diff. & Corr. & Diff. & Corr. & Diff. \\
\hline Beginning of vegetation of rye & 0.53 & -0.06 & 0.58 & -0.04 & 0.39 & 0.01 & 0.05 & -0.10 \\
\hline Stalk formation of rye & 0.47 & 0.00 & 0.49 & -0.05 & 0.37 & 0.08 & -0.02 & -0.10 \\
\hline Foliation of birch & 0.46 & -0.03 & 0.39 & -0.01 & 0.55 & 0.21 & -0.06 & -0.06 \\
\hline Blossoming of maple & 0.42 & 0.07 & 0.46 & -0.04 & 0.55 & 0.11 & 0.03 & -0.27 \\
\hline Blossoming of bird cherry & 0.51 & -0.06 & 0.53 & -0.19 & 0.53 & 0.09 & 0.14 & -0.30 \\
\hline Appearing of stalk node of rye & 0.51 & -0.12 & 0.54 & -0.02 & 0.37 & 0.09 & 0.02 & -0.26 \\
\hline Blossoming of apple tree & 0.44 & -0.18 & 0.48 & -0.40 & 0.43 & 0.02 & 0.32 & -0.33 \\
\hline Blossoming of lilac & 0.36 & -0.32 & 0.40 & -0.34 & 0.30 & -0.04 & 0.37 & -0.27 \\
\hline Blossoming of rowan & 0.35 & -0.37 & 0.37 & -0.35 & 0.29 & 0.04 & 0.35 & -0.33 \\
\hline Ear of rye & 0.40 & -0.27 & 0.48 & -0.30 & 0.32 & 0.05 & 0.35 & -0.27 \\
\hline Pollination of rye & 0.36 & -0.43 & 0.22 & -0.33 & 0.30 & 0.06 & 0.53 & -0.18 \\
\hline Milky ripeness of rye & 0.39 & -0.32 & 0.23 & -0.25 & 0.31 & 0.22 & 0.52 & -0.06 \\
\hline Waxy ripeness of rye & 0.31 & -0.36 & 0.20 & -0.34 & 0.31 & 0.07 & 0.44 & -0.08 \\
\hline Full ripeness of rye & 0.31 & -0.22 & 0.21 & -0.36 & 0.26 & 0.11 & 0.43 & -0.07 \\
\hline Harvesting of rye & 0.25 & -0.17 & 0.16 & -0.34 & 0.31 & 0.16 & 0.33 & -0.10 \\
\hline
\end{tabular}


Due to thermal inertia, correlation between start dates of late winter, early spring and spring has been observed. Therefore, the correlation coefficients in Table 2 are somewhat similar. The highest correlation is characteristic of start dates of climatic seasons and phenological phases that occur simultaneously. For example, the start date of late winter influences whether the following spring will be early or late. Early spring is associated with the start of vegetation and the subsequent phases of rye. Harvesting of rye usually takes place in August and is therefore not connected with the start dates of climatic seasons in springtime.

The start of spring (i.e. the thermal growing season) has the highest correlation with phenological phases, such as foliation of birch and blossoming of maple and bird cherry, which are observed from the end of April to the middle of May. Phenological development of rye is less strongly correlated with the start of spring. The start of summer is strongly correlated with late phases of rye at the end of May and in June. The longer the time interval from the beginning of a climatic season to the start of a phenological phase, the weaker the correlation between them.

To analyse the persistence of the correlation between the seasons and phases, the $50 \mathrm{yr}$ period was divided into 2 halves and the same correlation coefficients were calculated for them independently. Differences between correlation coefficients averaged over the 9 stations calculated for the periods 1972 to 1996 and 1947 to 1971 are presented in Table 2. They indicate that during the first period correlation was remarkably higher than during the second period.

The difference is especially high for correlation coefficients between late winter and early spring, and some phenological phases in May and June. Greater differences are typical also for the start dates of summer. This means that correlation coefficients calculated for the period 1972 to 1996 are substantially smaller than the coefficients found for the period 1947

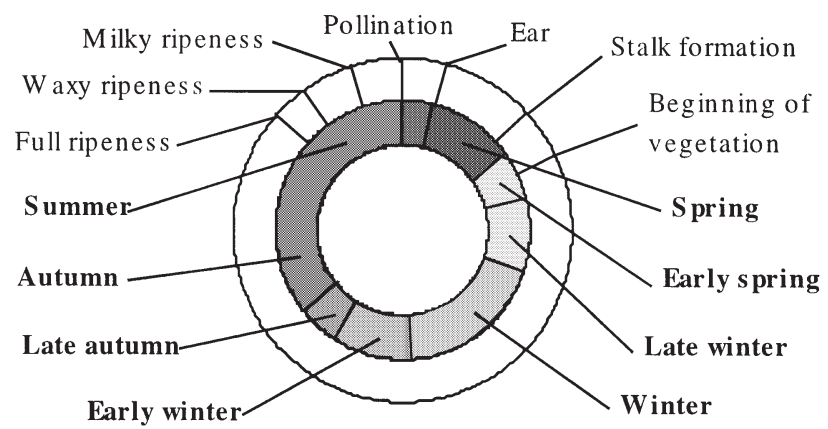

Fig. 5. Mean annual cycle of climatic seasons in Estonia (inner) and of phenological phases of autumn sown rye in spring and summer (outer) to 1971 . Only the start date of spring has a higher correlation in the more resent time series.

As a graphical summary of the results of the phenological calendar analysis, several phenological annual circles can be drawn. Fig. 5 presents the mean annual cycles of climatic seasons in Estonia and of the phenological phases of autumn sown rye in spring and summer. The cycle is oriented so that the winter solstice is located at the bottom, and the summer solstice is at the top, coinciding with the beginning of the pollination of rye. Time progresses counter-clockwise.

\section{TEMPORAL VARIABILITY OF THE LONG-TERM SERIES}

\subsection{Long-term trends in climatic seasons}

Long-term changes in climatic seasons were analysed using data from the Tartu station during the period 1891 to 1998. The time series and their linear trends are presented in Fig. 6. Statistics of the temporal variability of climatic seasons are shown in Table 3.

The lowest year-to-year variability is typical for the start dates of autumn and spring. This is probably due to the rapid change in the length of the day, sunshine duration, solar radiation, and air temperature during equinoxes at high latitudes.

Consequently, seasonal changes in living nature at that time are the fastest and most fixed in time in comparison with other times of the year. The highest temporal variability is characteristic for the beginning of early winter, winter and late winter. Greater cyclonic activity means that weather conditions are the most variable during the winter season.

Results of linear regression analysis of long-term series in Tartu indicate the presence of some long-term tendencies. Changes in trend in Table 3 are differences between trend values calculated for years 1998 and 1891. Negative changes show a tendency for climatic seasons to start earlier and vice versa.

Climatic seasons during the first half of the year tend to begin earlier, while seasons of the second half (except early winter) have been starting later. A statistically significant trend was determined only for the start date of late autumn and winter. Their start dates have shifted from 16 to 24 October and from 2 to 19 December, respectively. Trends in late winter and summer time series are not significant due to the high temporal variability of the time series.

Long-term variability of the duration of climatic seasons is even higher than that of start dates (Table 3). Duration is determined by 2 start dates and this increases its temporal variability. The durations of winter and early winter are the most variable. 


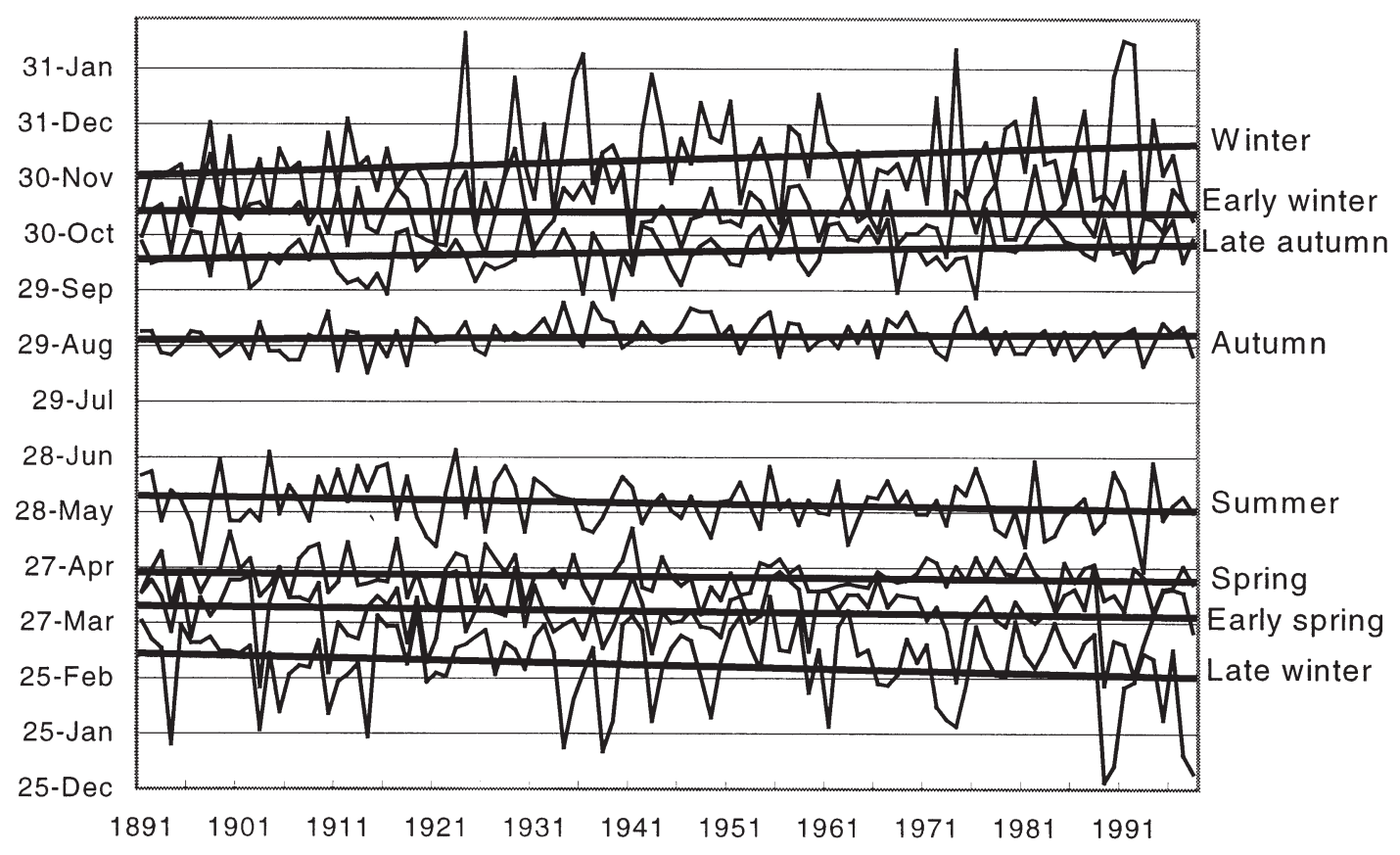

Fig. 6. Long-term series and linear trends for start dates of climatic seasons in Tartu (1891 to 1998)

The summer season has lengthened by $11 \mathrm{~d}$ during the 108 yr period. Other significant trends were obtained for early winter, winter and the whole thermal growing season. The shortening of the winter season by $30 \mathrm{~d}$ is significant even at $\mathrm{p}<0.01$ level. All the long-term tendencies observed at Tartu are in a good accordance with the trend of increasing mean air temperature during winter and spring seasons (Jaagus 1998), and with the trend of decreasing spatial mean snow cover duration (Jaagus 1997).

Long-term changes in climatic seasons are depicted in Fig. 7. The inner cycle represents the mean distribu- tion of the seasons by trend at the beginning of the period, and the outer cycle at the end. The obvious lengthening of summer and shortening of winter can easily be observed.

To analyse temporal fluctuations of the studied trends, the whole observation period was divided into 2 equal parts. The same statistical measures as in Table 2 were calculated for the periods 1891 to 1944 and 1955 to 1998. During the first period, significant positive trends at a $\mathrm{p}<0.01$ confidence level were found for the start dates of autumn and winter. They have shifted towards a later time by 12 and 27 days,

Table 3. Statistics of temporal variability for start date and duration of climatic seasons in Tartu between 1891 and 1998. Bold values: significant changes by linear trend at $\mathrm{p}<0.05$

\begin{tabular}{|c|c|c|c|c|c|c|c|c|}
\hline \multirow{2}{*}{$\begin{array}{l}\text { Climatic season } \\
\text { or period }\end{array}$} & \multicolumn{2}{|c|}{ Average } & \multicolumn{2}{|c|}{ Range } & \multicolumn{2}{|c|}{ Standard deviation } & \multicolumn{2}{|c|}{ Change in trend } \\
\hline & Start date & Duration & Start date & Duration & Start date & Duration & Start date & Duration \\
\hline Early spring & $2 \mathrm{Apr}$ & 20 & 69 & 65 & 14.7 & 14.0 & -6 & 1 \\
\hline Spring & 22 Apr & 41 & 48 & 81 & 10.0 & 16.7 & -5 & -3 \\
\hline Spring in total & & 61 & & 92 & & 18.5 & & -2 \\
\hline Summer & 2 Jun & 93 & 68 & 74 & 13.7 & 16.7 & -8 & 11 \\
\hline Autumn & $2 \mathrm{Sep}$ & 48 & 39 & 67 & 8.5 & 13.3 & 3 & 5 \\
\hline Late autumn & 20 Oct & 22 & 51 & 65 & 11.4 & 15.6 & 8 & -9 \\
\hline Autumn in total & & 70 & & 72 & & 15.4 & & -4 \\
\hline Early winter & $11 \mathrm{Nov}$ & 29 & 66 & 125 & 13.4 & 25.1 & -1 & 18 \\
\hline Winter & $11 \mathrm{Dec}$ & 82 & 118 & 136 & 25.3 & 32.5 & 17 & -30 \\
\hline Late winter & $3 \mathrm{Mar}$ & 30 & 104 & 88 & 21.9 & 19.2 & -13 & 7 \\
\hline Winter in total & & 141 & & 100 & & 20.6 & & -5 \\
\hline Growing season & & 182 & & 77 & & 16.3 & & 13 \\
\hline
\end{tabular}




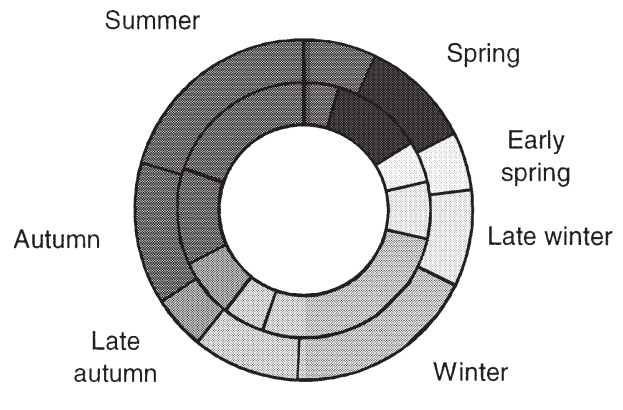

Early winter

Fig. 7. Annual cycle of climatic seasons in Tartu for 1891 (inner) and 1998 (outer) calculated by linear trend

respectively. The period 1945 to 1998 is characterised by a remarkable tendency for late winter and early spring to begin earlier (by 32 and $18 \mathrm{~d}$ ).

Generally, results of long-term trends of climatic seasons in Estonia coincide with results obtained for different sites in North Europe (Carter 1998) and in the former Soviet Union (Jones \& Briffa 1995). The duration of the thermal growing season has lengthened by $11 \mathrm{~d}$ in Tartu during the period 1891 to 1998 and by 1 to 3 wk in Fennoscandia between 1890 and 1995.

\subsection{Long-term trends in phenology}

Table 4 and Fig. 8 present the of temporal variability characteristics of some phenological phases observed in Paide (central Estonia) between 1919 and 1995 (Ahas et al. 1998). Long-term changes in phenological phases have trends similar to those of climatic seasons. The start of phenological phases has shifted to earlier in spring. All start dates have shifted to earlier, while the blossoming of wood anemone and of lilac have a trend significant at a $\mathrm{p}<0.05$ confidence level. Spring has advanced $7.5 \mathrm{~d}$ on average during the last $78 \mathrm{yr}$.

These results are similar to the changes in thermal growing season observed in Europe by the International Phenological Gardens (Menzel \& Fabian 1999). For example, leaf unfolding has advanced $6 \mathrm{~d}$ and leaf colouring in fall has been delayed by $4.8 \mathrm{~d}$ per $30 \mathrm{yr}$ of observations in Europe.

\section{DISCUSSION AND CONCLUSIONS}

\subsection{Determination of climatic seasons}

Seasonal changes in weather conditions usually proceed gradually. Therefore, it is not easy to separate climatic seasons in the annual cycle. In any case the choice is arbitrary. Traditional criteria for determining climatic seasons used over many decades in Estonia were applied in this study. They were specified and adapted only for the processing of a large amount of data. The results of this study, showing in general quite a close correlation between start dates of climatic seasons and phenological phases, confirm the validity of the criteria used.

The main disadvantage of using air temperature thresholds is that, in some cases, small differences in air temperature between neighbouring stations could lead to large differences in the start dates of climatic seasons. This happens when the seasonal change of air temperature is not gradual but oscillatory, with strong alternating positive and negative anomalies. Consequently, a climatic season can begin either on the rising (or falling) slope of the first wave or of the next one. The period of these temporal waves may be more than 1 mo.

The start dates of the studied phenological phases have a similar spatio-temporal pattern as the studied climatic seasons. These phases can be used to determine seasons in parallel with the temperature threshold method. Phenological phases are a result of natural factors causing seasonality in living nature; they delimit periods with similar weather conditions that can be observed as climatic seasons. Therefore, many authors use phenological phases for the determination of seasons (Schnelle 1955, Schultz 1981).

The use of temperature thresholds for the determination of the winter season is more contestable. Snow cover is a complex climatic and phenological phenomenon that is an even more important factor for characterising weather conditions in winter. It has a very great influence on plants, animals and human activity in Estonia.

In the regions of moderate continental climate, differentiation of early winter and late winter is justified.

Table 4. Statistics of temporal variability for start dates of phenological observation series in Paide from 1919 to 1995 . Bold values: significant at $\mathrm{p}<0.05$

\begin{tabular}{|c|c|c|c|c|c|c|c|}
\hline Phenological phase & Average & $\begin{array}{l}\text { Standard } \\
\text { deviation }\end{array}$ & $\begin{array}{c}\text { Earliest } \\
\text { date }\end{array}$ & $\begin{array}{c}\text { Latest } \\
\text { date }\end{array}$ & Slope & $\begin{array}{c}\text { Change in } \\
\text { trend }\end{array}$ & $t$-statistic \\
\hline Blossoming of wood anemone & 119 & 10.3 & 86 & 159 & -0.17 & -14 & -3.74 \\
\hline Blossoming of bird cherry & 139 & 8.7 & 121 & 161 & -0.05 & -4 & -1.29 \\
\hline Blossoming of apple & 147 & 9.0 & 127 & 169 & -0.05 & -3 & -1.10 \\
\hline Blossoming of lilac & 148 & 7.9 & 125 & 169 & -0.11 & -9 & -2.85 \\
\hline
\end{tabular}




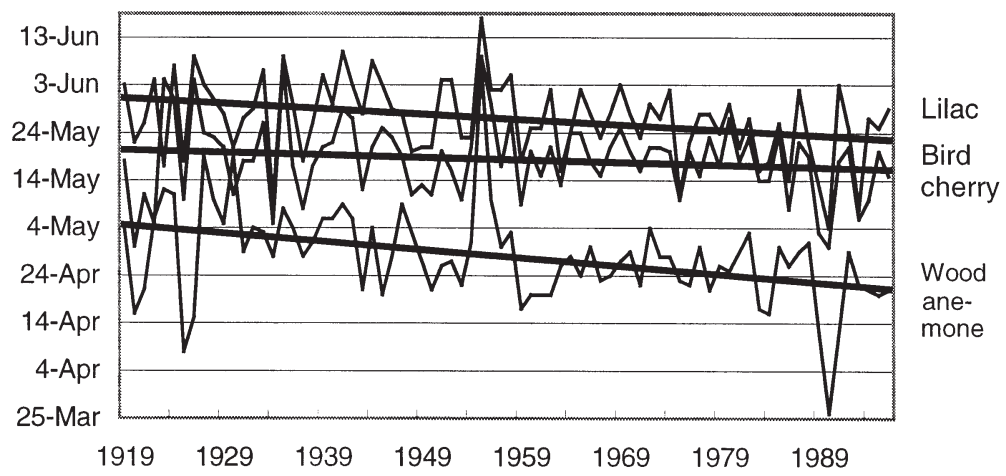

Fig. 8. Long-term series and linear trends of blossoming dates in Paide (1919 to 1995$)$

They present qualitatively different weather types and have a different impact on living nature. During mild winters, especially on the coasts of the West-Estonian Archipelago, permanent snow cover is not formed. In that case, it is better to distinguish one winter period including early and late winter seasons.

The criteria used for the determination of climatic seasons in Estonia can also be applied in other regions with a similar climate (snowy forest climate, Dfb, according to Köppen-Geiger). It can be assumed that they would work quite well in central latitudes of Fennoscandia and on the major parts of the East European plain. There is no sense in applying nor possibility to apply the same system of threshold values to the determination of climatic seasons for regions with different climate types. Phenological phases can serve as a more universal source for the determination of the natural seasons in large territories, for example, for all continental Europe (Schnelle 1955, Menzel \& Fabian 1999).

\subsection{Spatio-temporal variability}

Climatic seasons and phenological phases in Estonia are characterised by a remarkable variability in space and time. This is most pronounced during the winter season. The high year-to-year variations can be explained by high cyclonic activity in Northern Europe. Spatial differences are connected with high gradients of air temperature due to the influence of the Baltic Sea. As a rule, start dates of climatic seasons and phenological phases occur later on the coast than in the hinterland.

The Hopkins's bioclimatic law (Hopkins 1938) determines factors influencing the spatial distribution of phenological phases. It is oriented for North America but the main principles are also valid for Europe. The pattern of start dates of the climatic seasons and phenological phases in Estonia follows the same regularities. Onset of late winter and early spring seasons and phenophases spreads from southwest to northeast (Fig. 2), onset of spring and summer from southeast to northwest (Fig. 3), and onset of autumn from northeast to southwest (Fig. 4). The distribution of all phenological phases is similar to the general directions in Eastern and Northern Europe mapped by Schnelle (1955). Similar influence of the Baltic Sea is also noticeable in phenological maps of Finland (Heikinheimo \& Lappalainen 1997).

The results of the current study show that, as a rule, spatio-temporal variability of start dates of the climatic seasons is higher than that of phenological phases during the same period. It can be supposed that weather as an independent variable fluctuates within higher limits than phenological phases, which are influenced by weather conditions. Due to physiological peculiarities of plants and local natural conditions, phenological phases have an inertia that eliminates the influence of short-term weather fluctuations.

\subsection{Long-term changes}

Climatic seasons and phenological phases can be used as good indicators able to contribute new information to studies on climatic change. For example, mean air temperature in summer (JJA) has not increased during the last century in Estonia (Jaagus 1998). At the same time, the results of this study revealed a significant lengthening of the summer season and the thermal growing season-by 11 and $13 \mathrm{~d}$ respectively (Table 3, Fig. 7). The start of climatic seasons in the spring period has tended to shift to earlier and in the autumn period has shifted to later. Similar trends have been observed in the whole Nordic region (Carter 1998).

The same trends are also typical for long-term springtime phenological phases in Paide between 1919 and 1996 and other observation sites in Estonia (Ahas 1998, 1999). As a result, the spring onset of phenophases occurs significantly earlier by 3 to $14 \mathrm{~d}$ (Table 4 , Fig. 8). The greatest changes can be observed in early spring phases: pollination of hazel and blossoming of wood anemone. This result is similar to the results of analyses of the International Phenological Gardens network data for 1959 to 1993, which shows that spring phenophases have advanced by $6 \mathrm{~d}$ and autumn phenophases have been delayed by $4.8 \mathrm{~d}$ (Kramer 1996, Menzel \& Fabian 1999).

Correlation between start dates of climatic seasons and phenological phases in Estonia is high. In most 
cases, correlation coefficients are statistically significant at the $\mathrm{p}<0.05$ confidence level. The highest correlation is for seasons and phases that occur almost at the same time.

Acknowledgements. The authors are very grateful to 3 anonymous reviewers for their useful recommendations and critical comments, which were very helpful in improving the paper. This study was funded by the Estonian Science Foundation (Grant No. 3006).

\section{LITERATURE CITED}

Ahas R (1997) The impact of climatic changes on seasonal cycles in nature: the study of unusually late and early springs in Estonia. In: van de Geijn SC, Kuikman PJ (eds) International workshop on prospects for co-ordinated activities in core projects of GCTE, BAHC and LUCC, S.C., November 16-19, 1997, Wageningen. Wageningen Agricultural University, Wageningen, p 144-145

Ahas R (1999) Long-term phyto-, ornitho-, and icthyophenological time-series analyses in Estonia. Int $\mathrm{J}$ Biometeorol 42:119-123

Ahas R, Tarand A, Meitern H (1998) Temporal variability of the phenological time series in Estonia. In: Tarand A, Kallaste $\mathrm{T}$ (eds) Country case study on climate change impacts and adaptation assesments in the Republic of Estonia. Report to the UNEP/GEF; Project No. GF/220096-45. Stockholm Environment Institute-Tallinn, Tallinn, p 28-30

Alexandersson H (1986) A homogeneity test applied to precipitation data. J Climatol 6:661-675

Alexandersson H, Moberg A (1997) Homogenization of Swedish temperature data. Part I: homogeneity test for linear trends. J Climatol 17:25-37

Buishand TA (1982) Some methods for testing the homogeneity of rainfall records. J Hydrol 58:11-27

Carter TR (1998) Changes in the thermal growing season in Nordic countries during the past century and prospects for the future. Agric Food Sci Finland 7:161-179

Crick HQP, Sparks T (1999) Climate change related to egglaying trends. Nature 399:423-424

Drozdov OA, Vasilyev VA, Kobysheva NV, Raevskij AN, Smekalova LK, Shkol'nyj EP (1989) Klimatologija. Gidrometeoizdat, Leningrad (in Russian)

Flint HL (1974) Phenology and genecology of woody plants. In: Lieth H (ed) Phenology and seasonality modeling. Ecological Studies 8. Springer-Verlag, New York, p 83-97

Flohn H (1942) Witterung und Klima in Deutschland. Verlag von S Hirzel, Leipzig

Frich P, Alexandersson H, Ashcroft J, Dahlström B, Demarée GR, Drebs A, van Engelen AFV, Førland EJ, HanssenBauer I, Heino R, Jónsson T, Jonasson K, Keegan L, Nordli PØ, Schmidt T, Steffensen P, Tuomenvirta H, Tveito OE (1996) North Atlantic climatological dataset (NACD version 1) - Final Report. Scientific Report 96-1 Danish Meteorological Institute, Copenhagen

Galahov NN (1959) Study on structure of climatic seasons of a year. Izdatel'stvo Akademii Nauk SSSR, Moscow (in Russian)

Gerstengarbe FW, Werner PC (1999) Estimation of the beginning and end of recurrent events within a climate regime. Clim Res 11:97-107
Heikinheimo M, Lappalainen H (1997) Dependence of the flower bud burst of some plant taxa in Finland on effective temperature sum: implications for climate warming. Ann Bot Fennici 34:229-243

Hlavač V (1975) Eine neue Methode zur objektiven Beurteilung der Säkularen Schwankungen und Abnormalitäten der Lufttemperatur und der Sonnefleckenrelativzahlen und ihre Anwendung für die 200jährige Prager Temperaturreiche. Geofysikalni Sbornik 23:371-565

Hopkins AD (1938) Bioclimatics - a science of life and climate relations. US Dept Agr Misc Publ 280

Jaagus J (1996) Changes in climatological calendar during the last century in Tartu, Estonia. In: Wennerberg G (ed) European conference on applied climatology. Abstract volume, SMHI, Norrköping, p 128-129

Jaagus J (1997) The impact of climate change on the snow cover pattern in Estonia. Clim Change 36:65-77

Jaagus J (1998) Climatic fluctuations and trends in Estonia in the 20th century and possible climate change scenarios. In: Kallaste T, Kuldna P (eds) Climate change studies in Estonia. Stockholm Environment Institute-Tallinn, Tallinn, p 7-12

Jõgi J (1988) On seasonal rhythms in formation of micro-climate. In: Keskpaik A, Noorkõiv R (eds) Problems of geography in Estonia. Estonian Academy of Sciences, Tallinn, p 62-66 (in Estonian)

Jones PD, Briffa KR (1995) Growing season temperatures over the former Soviet Union. J Climatol 15:943-959

Kalnicky RA (1987) Seasons, singularities, and climatic changes over the midlatitudes of the Northern Hemisphere during 1899-1969. J Clim Appl Meteorol 26: 1496-1510

Kramer K (1994) Selecting a model to predict the onset of growth of Fagus sylvatica. J Appl Ecol 31:172-181

Kramer K (1996) Phenology and growth of European trees in relation to climate change. Thesis, Landbouw Universiteit Wageningen

Lamb HH (1972) Climate: present, past and future, Vol 1. Fundamentals and climate now. Methuen, London

Lewik P (1996) Thermal seasons of the year in Southern Poland-tendencies of the terms and duration. Zeszyty Naukowe Uniwersitetu Jagiellonskiego, Prace Geograficzne 102:355-358

Lieth H (1974) Purposes of phenology book. In: Lieth H (ed) Phenology and seasonality modeling. Ecological studies 8. Springer-Verlag, New York, p 3-19

Maak K, von Storch H (1997) Statistical downscaling of monthly mean air temperature to the beginning of flowering of Galanthus nivalis L. in Northern Germany. Int $\mathrm{J}$ Biometeorol 41:5-12

Menzel A, Fabian P (1999) Growing season extended in Europe. Nature 397:659

Moberg A, Bergström H (1997) Homogenization of Swedish temperature data. Part III: The long temperature records from Uppsala and Stockholm. J Climatol 17:667-699

Myneni RB, Keeling CD, Tucker CJ, Asar G, Nemani RR (1997) Increased plant growth in the northern high latitudes from 1981 to 1991. Nature 386:698-702

Owen DB (1962) Handbook of statistical tables. AddisonWesley Publishing Company, Reading, MA

Podolsky AS (1983) New phenology: elements of mathematical forecasting in ecology. John Wiley \& Sons, New York

Raik A (1963) Climatic seasons in Estonia. Acta Comm Univ Tartuensis 144:33-44 (in Estonian, summary in English)

Roltsch WJ, Zalom FG, Strawn AJ, Strand JF, Pitcairn MJ (1999) Evaluation of several degree-day estimation methods in California climates. Int J Biometeorol 42:169-176 
Schnelle F (1955) Pflanzen-Phänologie. Akademishe Verlagsgesellschaft, GEEST und PORTIG KG, Leipzig, p 166-210 Schultz GE (1981) General phenology. Nauka, Leningrad, p 91-146 (in Russian)

Schwartz MD (1998) Green-wave phenology. Nature 394: 839-840

Schwartz MD (1999) Advancing to full bloom: planning phenological research for the 21st century. Int J Biometeorol 42:113-118

Sladek I (1990) Changes of duration and timing of some temperature seasons of the year in Prague. In: Brazdil R (ed)

Editorial responsibility: Mike Hulme,

Norwich, United Kingdom
Climatic change in the historical and the instrumental periods. Masaryk University, Brno, p 194-196

Steffensen P (1996) Standard normal homogeneity test for Windows. User guide. Technical Report 96-13, Danish Meteorological Institute, Copenhagen

Temnikova NS (1958) Climate of the Latvian S.S.R. Gidrometeoizdat, Riga (in Russian)

White MA, Thorton PE, Running SW (1997) A continental phenology model for monitoring vegetation responses to interannual climatic variability. Global Biogeochem Cycles 11(2):217-235

Submitted: April 26, 1999; Accepted: March 10, 2000

Proofs received from author(s): July 13, 2000 